\title{
The Psychology of Foreign Language Vocabulary Acquisition: Implications for CALL
}

\author{
Nick C. Ellis \\ Department of Psychology, \\ University of Wales Bangor, \\ Bangor, \\ Gwynedd, \\ Wales LL57 2DG \\ UK \\ International Tel: +44 248382207 \\ International Fax: +44248382599 \\ e-mail: N.Ellis@bangor.ac.uk
}

To appear in

International Journal of Computer Assisted Language Learning (CALL)

1995 Special Issue on

Cognitive Aspects of Second Language Acquisition

Edited by

D. Green and P. Meara 


\section{Introduction}

Traditionally CALL programs have too often been driven by enthusiasm for what computers can be made to do and too rarely by an understanding of human cognition. They are not alone in attracting such criticism. Much of foreign language (FL) and second language (L2) instruction follows fashion rather than being informed by theory and refined after proper evaluation (Ellis, 1993). In this short review I will summarise current cognitive psychological knowledge concerning vocabulary acquisition and discuss implications for the development of effective computer assisted vocabulary acquisition methods.

I will argue that there are several aspects of vocabulary acquisition which involve qualitatively different learning processes. In particular I will demonstrate that (i) the acquisition of cognitive mechanisms for pattern recognition of written or spoken word forms, as well as of mechanisms for production of spoken or written FL, mainly involves implicit learning processes in specialised input and output modules whose operations are neither open to introspection nor affected by conscious hypotheses or beliefs, and (ii) the acquisition of lexical representations in these input/output (I/O) systems follows the power law of learning, being affected simply by frequency, recency, and context of exposure. In contrast, (iii) acquisition of word meanings requires explicit (conscious) learning processes; (iv) 'deep processing' strategies like semantic elaboration and imagery mediation result in better acquisition; and (v) the order of introduction of new vocabulary and the subsequent distribution of practice and testing can have profound effects on learning and memory.

\section{What is it to Learn a Word?}

What is it to learn a new word? Minimally we must recognise it as a word and enter it into our mental lexicon. But there are several lexicons specialised for different channels of Input/Output (I/O). To understand speech the auditory input lexicon must categorise a novel sound pattern (which will be variable across speakers, dialects, etc.); to read the word the visual input lexicon must learn to recognise a new orthographic pattern (or, in an alphabetic language, learn to exploit grapheme-phoneme correspondences in order to access the phonology and hence match the word in the auditory input lexicon); to say the word the speech output lexicon must tune a motor 
programme for its pronunciation; to write it the spelling output lexicon must have a specification for its orthographic sequence. We must learn its syntactic properties. We must learn its place in lexical structure: its relations with other words. We must learn its semantic properties, its referential properties, and its roles in determining entailments. We must learn the conceptual underpinnings that determine its place in our entire conceptual system. Finally we must learn the mapping of these $\mathrm{I} / \mathrm{O}$ specifications to the semantic and conceptual meanings.

There is no single process of learning a word. Rather these processes are logically, psychologically, and pedagogically separable.

\section{The Source of Vocabulary}

So how do we acquire our vocabulary? It is certainly the case that we have not been taught the vast majority of the vocabulary that we know, nor indeed have we looked up these words in dictionaries - most vocabulary is learned from context (Sternberg, 1987). There are, perhaps, 600,000 words in the English language. Smith (1982) uses the estimates of Seashore and Eckerson (1940) that the average college undergraduate knows about 156,000 of these words (58,000 'basic', 96,000 'derived', and 2,000 'rare') to emphasise that this knowledge could not have come from 156,000 trips to the dictionary, 156,000 flash cards, or 156,000 fill-in-the-blank exercises. It is difficult to validly estimate vocabulary size, and Nation (1993) suggests that, as a result of sampling problems, these estimates greatly exaggerate true vocabulary knowledge. But even if we take more conservative estimates such as that of 40,000 words suggested by Nagy \& Herman (1987), it is still clear that we have not been taught each of the words that we know.

Much of incidental vocabulary learning comes from context during reading: (1) People who read more know more vocabulary. This relationship between print exposure and vocabulary appears to be causal in that it holds even when intelligence is controlled (Stanovich \& Cunningham, 1992). (2) There are some 'Read and Test' studies which directly demonstrate that readers acquire vocabulary from text. For example, Saragi, Nation \& Meister (1978) asked adults to read Anthony Burgess' novel, “A Clockwork Orange”. This contains a number of novel words from a Russian-based slang called nadsat. There are 241 nadsat words in the novel and they are repeated on average 15 times. The subjects were simply asked to read the book (which crucially did not contain a dictionary of these words). A few days after finishing they were given a surprise 
test covering 90 nadsat words. Considerable vocabulary acquisition had taken place - Krashen (1989) estimated that subjects had picked up some 45 new words simply by reading a novel. (There are some problems with the generality of these studies since Burgess wrote the book intending the nadsat words to be learnable from context. Although supporting evidence of vocabulary acquisition from context are beginning to come forth (for example those of Sternberg, 1987 and Hulstijn, 1992 described later in this paper), Meara (1993) has persuasively argued that there is still need for these much-cited read-and-test studies to be replicated with other materials, larger samples, and tighter designs.)

Taking these results together, it seems that reading affords vocabulary acquisition. It is an ideal medium for it. Moderate-to-low-frequency words - precisely those words that differentiate between individuals of high and low vocabulary size - appear much more often in common reading matter than they do in common speech. And there is opportunity for the reader to study the context, to form hypotheses at leisure and cross validate them, to have time to infer meanings. The word is frozen in time on the page, whereas in speech it passes ephemerally.

Reading also gives us whole language, not just isolated words. McCarthy (1984) presented an influential critique of many vocabulary training programmes whose effect is an "atomized approach, an obsession with items and with definition, and an overall preoccupation with lexis at clause- and sentence- level" (p. 14). More recently, Clarke (1992) reiterated this criticism, but this time for CALL vocabulary programs. McCarthy advocates an alternative approach which lies in the examination of the syntagmatic and paradigmatic relations of collocation and set between items above sentence level, across conversational turn-boundaries, and within the broad framework of discourse organisation. In urging us to "bring to the forefront discourse values of lexis, and highlight such things as the textual establishment of synonymy and antonymy, equivalencies and contrasts, relations of inclusion, and so on" (p. 21), McCarthy proposed a number of games, turntaking, and text-building exercises which stress these relations. Experience of whole language, particularly the reading of reported discourse, shows the learner these relationships.

\section{The Processes of Vocabulary Acquisition: Some Alternative Hypotheses}

But what are the processes of vocabulary acquisition whilst adults read? There are various theories, the extremes being: 
1. An IMPLICIT vocabulary learning hypothesis holds that the meaning of a new word is acquired totally unconsciously as a result of abstraction from repeated exposures in a range of contexts. Krashen (1989) exemplifies this view. His Input Hypothesis assumes that we acquire language by understanding messages: "language is subconsciously acquired - while you are acquiring, you don't know you are acquiring; your conscious focus is on the message, not form. Thus, the acquisition process is identical to what had been termed 'incidental learning.' Also acquired knowledge is represented subconsciously in the brain - it is what Chomsky has termed 'tacit knowledge'." (Krashen, 1989, p. 440). If this position is correct and sufficient then it carries a clear implication for the role of CALL instruction in vocabulary acquisition, that is that CALL has no role other than as a means of exposing the learner to comprehensible input - it is no better, but currently a lot more expensive, than books.

2. An EXPLICIT vocabulary learning hypothesis holds that learners' acquisition of new vocabulary can be strongly facilitated by the use of a range of metacognitive strategies: (i) noticing that the word is unfamiliar, (ii) making attempts to infer the word from context (or acquiring the definition from consulting others or dictionaries or vocabularies), (iii) making attempts to consolidate this new understanding by repetition and associational learning strategies such as semantic or imagery mediation techniques. People are active processors of information. Contra Krashen (1989), it does not follow that vocabulary has been subconsciously acquired from the fact that we have not been taught the vast majority of the words that we know. That we have not been taught vocabulary does not entail that we have not taught ourselves. If this position holds then CALL has a considerable role to play.

\section{Implicit learning of I/O; Explicit learning of meaning}

What are language practitioners to make of these contradictory views? How can both be tenable? Does vocabulary come naturally or must it be taught and learned?

The answer is that both positions are true, but they apply to different aspects of vocabulary acquisition (Ellis, in press a,b). Humans are endowed with two dissociable learning abilities: implicit and explicit learning. Some things we just come to be able to do, like walking, recognising happiness in others, knowing that $t h$ is a more common than $t g$ in written English, or making simple utterances in our native language. We have little insight into the nature of the 
processing involved - we learn to do them implicitly like swallows learn to fly. Other of our abilities depend on our knowing how to do them, like multiplication, playing chess, speaking pig Latin, or using a computer programming language. We learn these abilities explicitly like aircraft designers learn aerodynamics.

Implicit learning is acquisition of knowledge about the underlying structure of a complex stimulus environment by a process which takes place naturally, simply and without conscious operations. Explicit learning is a more conscious operation where the individual makes and tests hypotheses in a search for structure. Knowledge attainment can thus take place implicitly (a nonconscious and automatic abstraction of the structural nature of the material arrived at from experience of instances), explicitly through selective learning (the learner searching for information and building then testing hypotheses), or, because we can communicate using language, explicitly via given rules (assimilation following explicit instruction).

One source of evidence for the dissociation between explicit and implicit learning comes from studies of global amnesic patients who, as a result of damage to structures in the middle of their brain (the hippocampus and limbic system), show normal implicit learning yet total anterograde amnesia for explicit and episodic memories (i.e. they lose the ability to consciously recollect any events that occur after their brain damage - see Schacter, 1987 for review). The perennial anecdotal evidence for this comes from Claparède (1911) who reported that he once shook hands with a female Korsakoff patient while concealing a pin in his hand. This caused the patient some pain, and when he returned a few minutes later and offered his hand again, she refused to shake it. Her avoidance continued, even though she could give no explanation of why she was avoiding him. In this case implicit learning (behaviour which is changed as a result of a previous encounter) is preserved in the absence of any conscious, explicit recollection of the event.

Amnesics retain implicit, automatic systems of learning in the absence of explicit, declarative learning. Their abilities of vocabulary acquisition can thus inform us about which processes are implicit and which explicit. In brief, their pattern is as follows:

1. They show normal implicit learning of the perceptual aspects of novel word forms. Thus input modules for recognising novel word forms are tuned by experience, and new pattern recognition units develop simply, implicitly, and automatically as a result of frequency of exposure. We should 
note that in these studies learners paid attention to the stimuli - although this is evidence for implicit learning, it does not demonstrate learning without awareness.

2. They show normal implicit learning of new motor habits and the motor aspects of novel word forms that are necessary for language production. Thus output modules for producing novel word forms are similarly tuned by experience, and new word production units (output logogens) also develop simply, implicitly, and automatically as a result of practice.

3. Yet amnesics are unable to learn the meaning of new words. They are severely deficient at developing new conceptual information and at making new semantic links. To the extent to which vocabulary acquisition is learning of this type (e.g. that aardvark - isan - armadillo ....., 'what's an aardvark?'), then this deficit in amnesia tells us that this type of vocabulary acquisition is explicit. In-between the implicit modules for receiving and producing language there is a conceptual system which operates according to cognitive principles, not those of habit. Explicit learning is involved in acquiring and processing word meanings.

The evidence of amnesia thus clearly demonstrates a clear dissociation: Mastering the mechanics of recognising and uttering a word and mastering the concept that it expresses are separate learning processes. Ellis (in press, a) presents a full review of this among a wide range of evidence demonstrating this dissociation between recognition and production aspects of vocabulary learning which rely on implicit learning, and meaning and mediational aspects of vocabulary which heavily involve explicit learning processes. In what follows here I will briefly discuss the implicit processes of vocabulary $\mathrm{I} / \mathrm{O}$ acquisition and then the explicit processes of the learning of word meanings.

\section{The Implicit Language Modules and their Role in Vocabulary Acquisition}

The I/O lexicons are acquired implicitly. Simple attention to the stimulus domain of words (the IMPLICIT hypothesis of 4.1) suffices for implicit learning mechanisms to induce statistical or systematic regularities in this input environment. Our lexical systems become tuned to regularities in orthography (letter units and sequential letter probabilities), to regularities in phonology (phonemes and phonotactic sequences), to regular patterns of grapheme-phoneme and phonemegrapheme correspondences, to high frequency words over low frequency ones, etc. Input modules recognise, and output modules produce, high frequency patterns faster as a result. The "golden 
rule of sensori-motor learning is much repetition" (Seibert, 1927, p. 309) - the more patterns are repeated, the more frequent they are, the better they are acquired.

One example of priming will have to suffice here in justifying this claim. Word recognition and word naming are faster if you have recognised or named that word within the last day. This occurs whether you explicitly remember having read the word before or not, and thus it demonstrates implicit memory - the tuning of the lexicon by experience. Furthermore it is unaffected by depth of processing. Jacoby and Dallas (1981) showed subjects a list of words and had them perform either a study task that required elaborative processing (e.g. answering questions about the meaning of the word) or a shallow study task that did not require elaborative processing (e.g. deciding whether or not the target word contained a particular letter). Explicit memory for the words was subsequently tested by yes/no recognition and implicit memory was assessed by savings in word identification tests. Recognition performance was higher following elaborative study than non-elaborative study. However, implicit memory was unaffected by the study manipulation: priming effects on word identification performance were about the same following the elaborative and non-elaborative tasks. Thus I/O operations like word identification operate according to implicit memory principles - they are affected by mere exposure and the frequency thereof. But, as will be demonstrated in the next section, explicit memory for words is clearly affected by the depth of processing and the degree to which subjects analyse meaning.

If we test vocabulary knowledge by tasks like speed of word naming, which fairly cleanly tap $\mathrm{I} / \mathrm{O}$ modules, then words which have a high frequency in the language, i.e. words which have had considerable life-span practice, are processed concomitantly faster. Kirsner (in press) proposes a life-span practice model to explain these frequency effects whereby lexical performance in children and adults, both in L1 (first language) and L2 (second language), can be explained simply by reference to the power law of learning which is generally used to describe the relationships between practice and performance in the acquisition of cognitive skills, be they perceptual or motor.

So, as with other skills, it is practice that makes perfect in the input and output modules, and, as Krashen (1989) championed, such practice is adequately provided from the job of language 
understanding. If CALL has a role here it is merely in providing another channel of comprehensible input.

\section{The Explicit Conceptual System and its Role in Vocabulary Acquisition}

In 1932 Bartlett, one of the founders of modern psychology, stated that "memory is an effort after meaning". A more recent statement of this theme is the Levels of Processing framework of Craik and Lockhart (1972). In this model, information can be encoded in multiple forms: e.g. in terms of semantic, phonemic, or visual features; in terms of verbal associates, or as an image. Information processing moves from a sensory level of analysis, through pattern recognition to semantic enrichment. Craik and Lockhart suggest that "memory trace persistence is a function of depth of analysis, with deeper levels of analysis associated with more elaborate, longer lasting, and stronger traces" (Craik and Lockhart, 1972, p. 675). Levels of Processing holds that shallow processing like oral rehearsal does not lead to long-term retention but deep processing, whereby semantic associations are accessed and elaborated, does.

Bower and Winzenz (1970) confirmed the usefulness of the two deep strategies of semantic and imagery mediation. Subjects learned to associate 15 arbitrary pairs of words (e.g. horse-cello) under one of four conditions: (i) Repetition: they were asked to verbally rehearse each pair, (ii) Sentence Reading: subjects saw each pair of words in a simple sentence, and were told to read it and use it to associate the two critical words, (iii) Sentence Generation: subjects were shown each pair of words and asked to construct and say aloud a meaningful sentence relating the two words, (iv) Imagery: subjects were asked to visualise a mental picture or image in which the two referents were in some kind of vivid interaction. The mean recall results in each condition were strikingly different: Repetition 5.6, Sentence Reading 8.2, Sentence Generation 11.5, Imagery 13.1 (all pairwise comparisons significant at or beyond $\mathrm{p}<.05$ ).

Deep processing mediational strategies are thus highly effective in long-term L1 learning. They are equally useful in L2 vocabulary learning. As Krashen (1989, p. 440) paradoxically argues: "Excellent reasons exist for devoting attention to vocabulary and spelling. First there are practical reasons. A large vocabulary is, of course, essential for mastery of a language. Second, language acquirers know this; they carry dictionaries with them, not grammar books, and regularly report that lack of vocabulary is a major problem." The larger one's vocabulary, the more one will 
understand of a language (Singer, 1965; Nagy \& Herman, 1987; Sternberg, 1987; Ellis \& Large, 1988). Thus even the advocates of communicative techniques - as opposed to formal teaching of grammar - agree that the growth of vocabulary, however it may be achieved, can only enhance the natural acquisition of language competence. So teachers recommend a variety of mnemonic techniques (Merry, 1980; Nattinger, 1988). Richards (1976), Brown (1980), Nation (1982, 1987), Carter (1987), Carter and McCarthy (1988), Chall (1987), Graves (1987), and Beck, McKeown and Omanson (1987) all advocate explicit vocabulary instruction, but by a range of means far beyond mere parrot fashion learning: Their recommended strategies include inference from context, consultation of dictionaries, collocation (combining words in high probability sequences in clichéd phrases), clines (e.g. scales such as cold/warm/hot expressed diagramatically), cloze procedures, card indices of new vocabulary, guessing skills and so on. The next sections present evaluations of such methods.

\subsection{Metalinguistic Strategies for Inferencing}

Although much vocabulary is learned from context during reading, word meanings do not come from mere exposure, rather, as Sternberg (1985, p. 307) argues, "simply reading a lot does not guarantee a high vocabulary. What seems to be critical is not sheer amount of experience but rather what one has been able to learn from and do with that experience. According to this view, then, individual differences in knowledge acquisition has priority over individual differences in actual knowledge." Jensen (1980, pp. 146-147) argues this position even more strongly: "Children of high intelligence acquire vocabulary at a faster rate than children of low intelligence, and as adults they have a much larger vocabulary, not primarily because they have spent more time in study or have been more exposed to words, but because they are capable of educing more meaning from single encounters with words... The crucial variable in vocabulary size is not exposure per se, but conceptual need and inference of meaning from context, which are forms of eduction." Learners can be profitably trained in strategies of eduction. Sternberg (1987) identified three basic subprocesses: selective encoding (separating relevant from irrelevant information for the purposes of formulating a definition), selective combination (combining relevant cues into a workable definition), and selective comparison (relating new information to 
old information already stored in memory). He categorised the types of available cue and moderating variables such as (i) the number of occurrences of the unknown word, (ii) the variability of contexts in which multiple occurrences of the unknown word appear, (iii) the importance of the unknown word to understanding the context in which it is embedded, (iv) the helpfulness of the surrounding context in understanding the meaning of the unknown word, and (v) the density of unknown words (too high a proportion of unknown words will thwart attempts to infer meaning). Subjects trained in use of these moderating variables or given practice in the processes of inferencing from context showed marked gains over control subjects in vocabulary acquisition from texts in a pretest-posttest Clockwork Orange design.

Not only does such training promote inferencing from context, but also this active derivation of meaning makes the vocabulary more memorable. Thus Hulstijn (1992) provides experimental support for a Levels of Processing hypothesis of vocabulary acquisition whereby inferred word meanings were retained better than those given to the reader through the use of marginal glosses.

\subsection{Dictionaries}

There is a more direct route to meaning than that of guessing from context. Learners can use a well-established technology for explicit instruction in word meanings, viz., dictionaries and thesauruses. But traditional dictionary definitions fall far short of providing complete word meanings. Meanings are concepts in the minds of people, whereas definitions are written by lexicographers. Traditional dictionary definitions relate lexicalized concepts to a string of other lexicalized concepts. They cannot give ostentive definitions, but rather provide a phrasal definition, and sometimes excerpts illustrating usage, from which they hope a reader can induce the intended concept. Definitions of polysemous words are particularly problematic.

Learning from a dictionary requires considerable cognitive sophistication. The learner must interrupt their reading, access the dictionary to find the unfamiliar word in an alphabetical list, all the time keeping the original context in mind so that they can compare it with the alternative senses given in the dictionary, and then select the sense that is most appropriate in the given context. This demanding process often leads to errors, even in L1. For example, Miller and Gildea (1991) show that children often fail to properly use dictionaries because of a naive strategy of 
substitution: after finding the unfamiliar word, they look for a familiar word or phrase among the definitions and then simply substitute the new word for this familiar word or phrase. For example, one fifth-grader who looked up the unfamiliar word erode, found the familiar phrases eat out and eat away in the definition and, generating the frame "Our family eats out a lot", produced the creative use of the new word: "Our family erodes a lot"!

CALL tools can provide solutions to these problems. (1) They can circumvent the hindrance of access. On-line dictionaries allow ready access to the lemma (the root form of the word: e.g. wants, wanted, and wanting can have their bound morphemes stripped off all to reveal the lemma want), and hyper-text links now enable users to access definitions simply by clicking on a word in the text. Thus the task of dictionary access does not interrupt understanding. (2) They can make available both the current context and the definition side-by-side on the screen. The user can readily switch attention between them, considerably reducing the load on working-memory. A study by Reinking \& Rickman (1990) demonstrates these two advantages - L1 6th graders acquired more novel words from reading passages if the texts were read from a computer screen which provided either optional or mandatory assistance with the meaning of target words than if they were read on printed pages accompanied by either a standard dictionary or glossary comprised of the target words. (3) The problem of naive substitution can be circumvented to some extent by the dictionary giving examples of usage on top of a simple definition. There are now several evaluations comparing contextual and definitional CALL on-line vocabulary instruction. Markham (1989) showed with advanced ESL students that whereas definitional knowledge is important in developing the basic concept of the word, context-embedded vocabulary exercises facilitated better long-term retention of words that exist in context. Similarly, Kolich (1991) demonstrated that 11th grade L1 students profited more in acquiring unfamiliar words from CALL software that provided sentence context, definitional or synonym cues, and optional word choices than from that which gave definitional information only. (4) When learners are reading, their primary motivation is the understanding of the text rather than the study of the range of nuances of unfamiliar words - when they come upon a novel word they want to know its particular sense in this particular context. Artificial Intelligence is not yet ready to provide the real-time natural language understanding running on desk-top machines necessary for an interface 
to disambiguate and select the relevant sense from an on-line dictionary. But with texts which have previously been analysed, a computer can be programmed to answer questions about the meaning of all of the words in the material. Miller \& Gildea (1991) report some initial explorations demonstrating the effectiveness of such hypertext passages where the click of a mouse can provide instant explanations, pronunciations, and even pictures indicating what the word denotes in the context. These also suggest that sentences illustrating the meaning of a novel word in this context can be more beneficial than broad definitions. When some children are given a definition, they quickly read it and return to the story. When they are given a sentence that is relevant to the story and which uses the word in the same context, they interpret it as a puzzle to be solved, spend more time thinking about it, and this deep processing and elaboration results in them remembering it better one week later.

There are clearly many benefits for vocabulary acquisition from CALL provision of on-line dictionaries, contextual examples of usage, and synonym, antonym and other associative thesaural information.

\subsection{Imagery Mediation using Keyword Methods}

Whether they access the meaning by inference from context, by asking someone, or by looking the word up in a dictionary, learners must consolidate a new word if it is not to be an 'ephemeral knowing'. Deep-processing techniques can serve as highly effective mnemonics.

Atkinson and Raugh (1975) compared learning of FL vocabulary by means of keyword mnemonics with a control condition in which subjects used their own strategies. Keyword condition subjects were presented with a Russian word and its English translation together with a word or phrase in English that sounded like the Russian word. For example, the Russian word for battleship is linkór. American subjects were asked to use the word Lincoln, called the keyword, to help them remember this. Subjects who used the keyword method learned substantially more translations than a control group and this advantage was maintained up to six weeks later.

In this method the first stage of recalling the meaning of a foreign word involves the subject remembering the native keyword which sounds like the foreign word. The second stage involves accessing an interactive image containing the referent of the keyword and 'seeing' the object with 
which it is associated (this is the equivalent of the Imagery mediation condition of Bower \& Winzenz, 1970). By naming this object the learner accesses the native translation. This two-stage route serves as a crutch in early mediation; with enough use the link between FL word and native translation becomes direct.

Although it is a highly effective technique (see Levin \& Presley, 1985 for review) and has been shown to work in CALL incarnations (Ellis \& Beaton, 1993a, b), the method has some limitations: (i) it is of little use with abstract vocabulary and keywords of low imageability, (ii) it is much less effective in productive vocabulary learning than in learning to comprehend the L2 because imagery association in the keyword technique allows retrieval of a keyword which is merely an approximation to the L2 form (Ellis \& Beaton, 1993a, b). The keyword technique does not have any in-built 'mnemonic tricks' to help spelling or pronunciation. As described in section 6, for effective productive vocabulary learning the keyword technique must be complemented with repetitive practice at producing the L2 word forms. In sum, imagery mediation does not contribute to the lexical productive aspects of L2, but it does forge L1-L2 linkages.

\subsection{Semantic Mediation}

(a) Using keywords

Sometimes FL words just remind us of the native word, a factor which usually stems from languages' common origins or from language borrowing. Thus the German Hund (dog) may be more easily retained than the French chien because of its etymological and sound similarity with the English hound. Such reminding, whether based on orthography, phonology, etymology or borrowing (e.g. 'le hot-dog') typically facilitates the learning of that FL word.

If the reminding is not naturally there, one can create it using keywords and semantic rather than imagery mediation. By simply remembering the keyword and the native word in a mediating sentence it is possible to derive the translation (the equivalent of the Sentence Generation condition of Bower \& Winzenz, 1970).

\section{(b) Deep Processing and Elaboration}


Beck, McKeown, and Omanson (1987) proposed that learners should focus on the meaning of new words and integrate them into pre-existing semantic systems, i.e., in Craik and Lockhart's terms, learners should be deep processors. Crow and Quigley (1985) evaluated the effectiveness for ESL students of several such semantic processing strategies (such as the 'semantic field' approach where subjects manipulated synonyms along with the target words in meaningful sentences) and found them to be superior to 'traditional methods' over long time periods.

It can be advantageous to combine keyword reminders and elaborative processing. Brown and Perry (1991) contrasted three methods of instruction for Arabic students' learning of English vocabulary. The keyword condition involved presenting the new word, its definition, and a keyword, and learners were given practice in making interactive images; the semantic condition presented the new word, its definition, two examples of the word's use in sentences, and a question which they were required to answer using the new word; the keyword-semantic condition involved all of these aspects. A delayed testing over a week later demonstrated that the combined keyword-semantic strategy increased retention above the other conditions.

\subsection{Summary Conclusions}

Stahl and Fairbanks (1986) performed a meta-analysis of nearly one hundred independent studies comparing the effectiveness of vocabulary instruction methods. This showed that the body of evaluative research to that data demonstrated (1) that vocabulary instruction is a useful adjunct to natural learning from context; (2) that the methods which produced highest effects on comprehension and vocabulary measures were those involving both definitional and contextual information about each to-be-learned word; (3) that several exposures were more beneficial for drill-and-practice methods; (4) that keyword methods produced consistently strong effects; and (5) that methods which provided a breadth of knowledge about each to-be-learned word from multiple contexts had a particularly good effect on later understanding of texts incorporating these words (rather than on tests which merely demanded accurate echoing of learned vocabulary definitions).

Taking their results together with the more recent ones reviewed here, it is clear that it truly matters what learners do in order to acquire the meaning of a new word. Successful learners use 
sophisticated metacognitive knowledge to choose suitable cognitive learning strategies appropriate to the task of vocabulary acquisition. These include: inferring word meanings from context, effective use of dictionary and thesaural aids, semantic or imagery mediation between the FL word (or a keyword approximation) and the L1 translation, and deep processing for elaboration of the new word with existing knowledge. As far as the meaning of vocabulary is concerned, an IMPLICIT vocabulary learning hypothesis does not hold, and therefore CALL has very useful roles to play in all of these different ways of promoting vocabulary acquisition.

\section{Repetition and How to Distribute Practice and Tests}

Learners frequently learn lists of vocabulary whether encouraged to do so or not (Carroll, 1963; Rodgers, 1969; Nation, 1987). They do it because it works: without too much effort the student can learn well over 30 words per hour by studying lists of vocabulary (Thorndike, 1908; Webb, 1962; Crothers \& Suppes, 1967; Nation, 1982; Krashen, 1989, Appendix II). From their earliest use in education, computers have had a role in managing programmed learning of this type.

If computers are to be used to aid active learning of vocabulary, whether this involves mere drill and practice, or more sophisticated mediational and mnemonic help, or routine testing and revision, then what is the most effective structuring of learning trials? Given a set of $n$ words to be learned, how should the $n$ items be ordered? Should item 1 be re-presented until it is mastered before item 2 is introduced, and so on? Alternatively should the sequence $1 . . . n$ be repeated until the whole set is acquired correctly? Does testing itself, without representation of the correct translation, afford any learning benefit? These questions have been thoroughly investigated over the last century and the answers are well known. Unfortunately they are rarely applied.

\subsection{The spacing effect}

The spacing effect is one of the most robust phenomena in experimental psychology: for a given amount of study time, spaced presentations yield substantially better learning than do massed presentations. It is better to distribute practice. In many cases two spaced presentations are about twice as effective as two massed presentations, and the difference between them increases as the frequency of repetition increases (Melton, 1970; Underwood, 1970). This effect 
was apparent in of the earliest of experimental studies of learning and memory performed by Ebbinghaus (1885) who concluded that "with any considerable number of repetitions a suitable distribution of them over a space of time is decidedly more advantageous than the massing of them at a single time". It was soon being passed on to educators; for example, William James (1901) advised teachers and students that it is better to repeat an association on many different days than again and again on just a few days. Yet despite the power of this effect, it is rarely realised by implementation in educational programmes, whether text- or CAL-based (Dempster, 1988).

Although the spacing effect is found for all sorts of learning, I will illustrate it here with a few studies specifically related to vocabulary. A small but clear demonstration is that of Bloom \& Shuell (1981) who investigated high school students' learning of French vocabulary which was presented either as massed practice (one 30 minute period) or distributed practice (three 10 minute periods over three successive days). The students who learned the words by distributed practice did substantially better (35\%) than the massed practice students on a delayed test 4 days later. For the case of programmed learning, Reynolds \& Glaser (1964) studied repetition effects and spaced review of biological terms related to mitosis (teleophase, spindles, equator, etc.) in sequences of instruction viewed by American junior-high-school students. Stimulus-response repetition differences as large as $200 \%$ had only a slight effect upon retention of programmed materials after a period of interpolated learning, and even this limited effect disappeared over a relatively short period of time. However, distribution of practice produced reliably superior retention in excess of $50 \%$ more than massed practice. Spacing of repetitions can be more important than number of repetitions.

Convincing and ecologically valid demonstrations come from the work of Bahrick who has studied vocabulary learning and its retention over periods of up to fifty years (e.g., Bahrick, 1984). Two of his studies addressed the spacing effect. Bahrick \& Phelps (1987) contrasted the effects of spaced training sessions (either 30 days, 1 day, or 0 intersession interval where a new retraining session immediately followed the previous one) on the learning of 50 English-Spanish word pairs. The training of some individuals thus took place over up to 8 months while others completed it in one day. Of course, the longer intersession intervals slowed down initial 
acquisition - an average of 5.5 word-pair presentations was needed for initial learning with 30-day intervals compared with 3.0 for the 0 intersession schedule. But this was far outweighed by the large and powerful effect of intersession interval on retention eight years later: 30-day interval training producing $250 \%$ the level of recall achieved after 0 intersession intervals. This trade-off confirms the importance of Meara's (1984) caution that too many studies of vocabulary acquisition only investigate rate of initial acquisition and retention over short time periods. In Bahrick \& Phelps as elsewhere (e.g. Atkinson, 1972) factors which increase initial rate of acquisition may actually prejudice against long-term retention. As Schmidt \& Bjork (1992, p. 207) state: "Manipulations that maximize performance during training can be detrimental in the long term; conversely, manipulations that degrade the speed of acquisition can support the longterm goals of training". It follows that we cannot necessarily use rate of acquisition as an index of long-term retention.

Further demonstrations of the power of spacing of practice come from Bahrick, Bahrick, Bahrick and Bahrick (1993). They studied retention of 300 English-foreign language word pairs 5 years after initial learning which involved either 13 or 26 relearning sessions administered at intervals of 14,28 , or 56 days. The longer intersession intervals slowed down acquisition slightly, but the disadvantage during training was offset by substantially higher retention. Thirteen retraining sessions spaced at 56 days yielded long-term recall comparable to 26 sessions spaced at 14 days.

Thus the spacing effect holds over relatively short periods and even more so over the life span. It is too powerful for instructional programmes to ignore.

\subsection{Testing and the Retrieval Practice Effect}

Successful recall of a vocabulary item can have two independent benefits for future learning and retention: (1) The first is quite straightforward - knowledge of recallability can be used to guide future learning, i.e. to treat recalled and unrecalled items differently, concentrating attention on the latter upon representation of material. This metamnemonic skill of monitoring our own performance (Kail, 1979) has been exploited in CALL vocabulary programs where subjects who can decide which items next to study do better than those who are presented with the items in 
random order (e.g. Atkinson, 1972, who also demonstrated that computer-controlled monitoring of item difficulty and learner progress using a mathematical model of optimal item ordering could result in even better performance than that under learner control). (2) The second benefit is perhaps more paradoxical. Periodic retrieval can have a very large effect on enhancing and stabilising long-term retention since encoding operations usually assumed to take place during item presentation can occur equally well following item recall (Thompson, Wenger \& Bartling, 1978). In other words, the very act of recalling something facilitates its subsequent recall - a test without feedback may be as beneficial or even more beneficial to long-term learning than a second presentation. This also is a very reliable effect (see Rea \& Modigliani, 1988; Baddeley, 1990 for reviews).

There are two separable aspects of this retrieval practice effect. (i) Modigliani (1976) showed that testing has a potentiating effect only for items that are successfully recalled. That is, an item that is recalled is strengthened by that recall and is therefore more likely to be recalled again later. However, an item not recalled on that test has an extremely low probability of being recalled on a later test (in the absence of further intervening study). (ii) The degree to which a recalled item is strengthened increases with the length of the interval preceding the test. If a vocabulary pair is tested immediately and correctly recalled, this has less benefit than if it is successfully recalled after a delay (Landauer \& Eldridge, 1967; Whitten \& Bjork, 1977; Rea \& Modigliani, 1988). These two factors have opposing temporal gradients and thus they generate a test spacing effect which has a somewhat qualified time-course from that of the study spacing effect. The first factor, i.e. the probability of the test event actually constituting a second input because it leads to recall, is inversely related to time - make the interval too long and the item will be forgotten. The second factor, the effect of spacing on study, is positively related with time - as explained above, net facilitation from two successive inputs increases with the interval between them.

These findings have important implications for the design of a series of tests that are spaced in a maximally effective manner. Specifically, the spacing of intervals between tests should be of an expanding nature - the interval between item presentation and the first test should be short, that between the first and second test somewhat longer, and so on. The probability of successful recall 
on the first test is high since the initial interval is short. The successful recall strengthens the recalled item, allowing it to be remembered over the second interval which is longer than the first, and so on. In such expanded series, the probability of successful recall is maintained at a high level throughout and, in addition, the potentiated effect of testing increases as the intervals between the tests are increased (Rea \& Modigliani, 1988). Landauer and Bjork (1978) experimentally evaluated this strategy of expanded rehearsal. Material was either presented once (P), four times, each separated by three other items $(3,3,3,3)$, or on an expanding rehearsal schedule in which the number of items between successive test presentations was increased $(0,1,3,8)$. Whereas the $(3,3,3,3)$ schedule gave a $50 \%$ improvement in long-term memory over $(\mathrm{P})$, the expanding rehearsal schedule $(0,1,3,8)$ which incorporated the same number of test repetitions gave a $100 \%$ improvement.

Expanding rehearsal (otherwise known as increasing ratio review) has been shown to be effective with a wide range of materials and learners. It has also been evaluated in the particular case of CALL programs - Siegel \& Misselt (1984) incorporated it into their computer-based Japanese FL vocabulary instructional programs and showed it to be superior to traditional review techniques.

In sum, the sequence of learning opportunities can have a dramatic effect on long-term retention: (1) distributed practice is superior to massed practice; and (2) successful retrieval can facilitate long-term memory as much as or more than another learning presentation. These effects can be combined into the broadly applicable, simple, but mnemonically powerful treatment of increasing ratio review: a given item should be initially tested after a brief delay; if the learner successfully recalls it, then the delay should be systematically increased; whereas if the learner is wrong the delay should be shortened. Given the reactive demands of the schedule, its management can become complex, but fortunately, computer algorithms can easily perform the required bookkeeping and optimise the ordering. This does not just apply to drill-and-practice. The basic principles underlying optimal distribution of practice have been demonstrated to be generally applicable. And, as for the retrieval effect, whenever we ask someone to tell us something that might be retrievable from our own memory, we rob ourselves of a learning opportunity (Bjork, 1988, p. 398). 


\section{Conclusions}

Learners must acquire the $\mathrm{I} / \mathrm{O}$ of new vocabulary: the pronunciation elements and their compounds in the tongue as well as the graphemes and their patterns of orthographic combination in the script. There are specialised modules, the input and output lexicons, which acquire the word forms and regularities of the surface form of language by implicit learning processes. Like other sensory or motor skill systems, these modules do so automatically and they are tuned by practice. To the extent that vocabulary acquisition is learning these surface forms of language then vocabulary acquisition is an implicitly acquired skill. In saying this I am not denying that the tunings of these systems cannot be guided by practice governed by explicit knowledge. In the same way that verbal declarative knowledge can coach the learner driver ('ease off the accelerator, down with the clutch, etc.'), so it can the learner speller ('i before $e$ except after $c . .$. '). In the early stages of any skill we use conscious declarative knowledge on the way to automatization. But essentially we learn to drive by driving itself, just as we learn to spell on the job of spelling or speak by speaking. In the main, these aspects of vocabulary acquisition reflect implicit learning.

However, the function of words is meaning and reference. And the mapping of I/O to semantic and conceptual representations is a cognitive mediation dependent upon explicit learning processes. It is heavily affected by depth of processing and elaborative integration with semantic and conceptual knowledge. Metacognitively sophisticated language learners excel because they have cognitive strategies for inferring the meanings of words, for enmeshing them in the meaning networks of other words and concepts and imagery representations, and mapping the surface forms to these rich meaning representations. To the extent that vocabulary acquisition is about meaning, it is an explicit learning process.

Reading provides an ideal environment for the implicit acquisition of orthography and also the explicit acquisition of meanings. It is now clear that CALL tools such as on-line dictionaries providing definitions, contextual examples of usage, and associative thesaural information, strongly facilitate vocabulary growth. Further benefit can be had from CALL tutoring in the metacognitive and cognitive skills of inferring meanings from contexts, But many are the times when we have discovered a word's meaning, either from text or from a dictionary, only for it to 
fade from our memory. Explicit, deep, elaborative processing involving semantic and conceptual/imaginal representations prevents this. CALL has numerous roles in the general training of explicit skills for memorising the meanings of vocabulary, and in the particular presentations of mnemonic mediators for specific items of vocabulary. Finally, we must not forget the traditional educational role of computers as programmed providers of drill, practice, and test. There is a role for sitting down and learning vocabulary, particularly in the early stages of FL learning. Computers can structure training, practice, and testing to optimise the rate of vocabulary acquisition. 


\section{References}

Atkinson, R.C. (1972). Optimizing the learning of a second-language vocabulary. Journal of Experimental Psychology, 96, 124-129.

Atkinson, R.C., \& Raugh, M.R. (1975). An application of the mnemonic keyword method to the acquisition of a Russian vocabulary. Journal of Experimental Psychology: Human Learning and Memory, 104, 126-133.

Baddeley, A.D. (1990) Human Memory: Theory and Practice. Hove, Sussex: Lawrence Erlbaum Associates.

Bahrick, H.P. (1984). Semantic memory content in permastore: Fifty years of memory for Spanish learned in school. Journal of Experimental Psychology: General, 113, 1-29.

Bahrick, H.P., \& Phelps, E. (1987). Retention of Spanish vocabulary over 8 years. Journal of Experimental Psychology: Learning, Memory and Cognition, 13, 344-349.

Bahrick, H.P., Bahrick, L.E., Bahrick, A.S., \& Bahrick, P.E. (1993). Maintenance of foreign language vocabulary and the spacing effect. Psychological Science, 4, 316-321.

Bartlett, F.C. (1932). Remembering: A Study in Experimental and Social Psychology. Cambridge: Cambridge University Press.

Beck, I.L., McKeown, M.G., \& Omanson, R.C. (1987). The effects and use of diverse vocabulary instruction techniques. In M.G. McKeown \& M.E. Curtis (Eds.), The Nature of Vocabulary Acquisition (pp. 147-163). Hillsdale, N.J.: Lawrence Erlbaum.

Bjork, R.A. (1988). Retrieval pratice and the maintenance of knowledge. In M.M. Gruneberg, P.E. Morris, \& R.N. Sykes (Eds.), Practical Aspects of Memory: Current Research and Issues. Volume 1: Memory in Everyday Life (pp. 396-401). Chichester: Wiley.

Bloom, K.C., \& Shuell, T.J. (1981). Effects of massed and distributed practice on the learning and retention of second-language vocabulary. Journal of Educational Research, 74, 245-248.

Bower, G.H., \& Winzenz, D. (1970). Comparison of associative learning strategies. Psychonomic Science, 20, 119-120.

Brown, D. (1980). Eight Cs and a G of Vocabulary Teaching. Guidelines for Vocabulary Teaching. RELC Journal Supplement, 3. Singapore: RELC. 
Brown, T.S., \& Perry, F.L. Jr. (1991). A Comparison of three learning strategies for ESL vocabulary acquisition. TESOL Quarterly, 25, 17-32.

Carroll, J.B. (1963). Research on teaching foreign languages. In N.L. Gage (Ed.), Handbook of Research on Teaching (pp. 1060-1100). New York: Rand McNally.

Carter, R. (1987). Vocabulary: Applied Linguistic Perspectives. London: Allen \& Unwin.

Carter, R., \& McCarthy, M. (1988). Vocabulary and Language Teaching. London: Longman.

Chall, J.S. (1987). Two vocabularies for reading: recognition and meaning. In M.G. McKeown \& M.E. Curtis (Eds.), The Nature of Vocabulary Acquisition. (pp. 1-18). Hillsdale, N.J.: Lawrence Erlbaum.

Claparède, E. (1911). Reconnaissance et moitié. Archives de Psychologie Genève, 11, 79-90.

Clarke, M. (1992). Vocabulary learning with and without computers: Some thoughts on a way forward. CALL, 5, 139-146.

Craik, F. I. M., \& Lockhart, R.S. (1972). Levels of processing: A framework for memory research. Journal of Verbal Learning and Verbal Behaviour, 11, 671-684.

Crothers, E., \& Suppes, P. (1967). Experiments in Second-Language Learning. New York: Academic Press.

Crow, J.T., \& Quigley, J.R. (1985). A semantic field approach to passive vocabulary acquisition for reading comprehension. TESOL Quarterly, 19, 497-513.

Dempster, F.N. (1987). Effects of variable encoding and spaced presentations on vocabulary learning. Journal of Educational Psychology, 79, 162-170.

Dempster, F.N. (1988). The spacing effect: A case study in the failure to apply the results of psychological research. American Psychologist, 43, 627-634.

Ebbinghaus, H. (1913). Memory (H.A. Ruger \& C.E. Bussenius, Trans.). New York: Teachers College. (Original work published 1885).

Ellis, N.C. (1993). Rules and instances in foreign language learning: Interactions of explicit and implicit knowledge. European Journal of Cognitive Psychology, 5. 289-318.

Ellis, N.C., \& Beaton, A. (1993). Factors affecting the learning of foreign language vocabulary: Imagery keyword mediators and phonological short-term memory. Quarterly Journal of Experimental Psychology. 46A, 533-558. 
Ellis, N.C., \& Beaton, A. (1993). Psycholinguistic determinants of foreign language vocabulary learning. Language Learning, 43, 559-617.

Ellis, N.C., \& Large, B. (1988). The early stages of reading: A longitudinal study. Applied Cognitive Psychology, 2, 47-76.

Ellis, N.C. (In press, a). Vocabulary acquisition: How implicit, how explicit? In N. Ellis (Ed.) Implicit and Explicit Learning of Languages. London: Academic Press.

Ellis, N.C. (Ed.) (In press, b). Implicit and Explicit Learning of Languages. London: Academic Press.

Graves, M.F. (1987). The roles of instruction in fostering vocabulary development. In M.G. McKeown \& M.E. Curtis (Eds.), The Nature of Vocabulary Acquisition (pp. 165-184). Hillsdale, N.J.: Lawrence Erlbaum.

Hulstijn, J. (1992). Retention of inferred and given word meanings: Experiments in incidental vocabulary learning. In P. Arnaud \& H. Bejoint (Eds.), Vocabulary and Applied Linguistics. (pp. 113-125). London: Macmillan.

Jacoby, L.L., \& Dallas, M. (1981). On the relationship between autobiographical memory and perceptual learning. Journal of Experimental Psychology: General, 110, 306-340.

James, W. (1901). Talks to teachers on psychology: And to students on some of life's ideals. New York: Holt.

Jensen, A. (1980). Bias in Mental Testing. New York: Free Press.

Kail, R. (1979). The Development of Memory in Children. San Francisco: W.H. Freeman.

Kirsner, K. (in press). Implicit processes in second language learning. In N. Ellis (Ed.), Implicit and Explicit Learning of Languages. London: Academic Press.

Kolich, E.M. (1991) Effects of computer-assisted vocabulary training on word knowledge. Journal of Educational Research, 84, 177-182.

Krashen, S.D. (1989). We acquire vocabulary and spelling by reading: Additional evidence for the Input Hypothesis. The Modern Language Journal, 73, 440-464.

Landauer, T.K., \& Bjork, R.A. (1978). Optimum rehearsal patterns and name learning. In M.M. Gruneberg, P.E. Morris, \& R.N. Sykes (Eds.), Practical Aspects of Memory (pp. 625-632). London: Academic. 
Landauer, T.K., \& Eldridge, L.. (1967). Effects of tests without feedback and presentation-test interval in paired-associate learning. Journal of Experimental Psychology, 75, 290-298.

Levin, J.R., \& Pressley, M. (1985). Mnemonic vocabulary acquisition: What's fact, what's fiction? In R.F. Dillon (Ed.), Individual Differences in Cognition (Vol. 2, pp. 145-172). Orlando, FL: Academic Press.

Markham, P. (1989). Effects of contextual versus definitional computer-assisted vocabulary instruction on immediate and long-term vocabulary retention of advanced ESL students. Educational Psychology, 9, 121-126.

McCarthy, M.J. (1984) A new look at vocabulary in EFL. Applied Linguistics, 5, 12-22.

Meara, P. (1980). Vocabulary acquisition: a neglected aspect of language learning. Language Teaching and Linguistics, 13, 221-246.

Meara, P. (1984) The study of lexis in interlanguage. In A. Davies, C. Criper and A. Howatt (Eds.) Interlanguage. Edinburgh: University of Edinburgh Press.

Meara, P. (1993). Assumptions about vocabulary acquisition, and where they come from. Keynote presentation, 10th World Congress of the International Association of Applied Linguistics, Amsterdam, August, 1993.

Melton, A.W.. (1970) The situation with respect to spacing of repetitions and memory. Journal of Verbal Learning and Verbal Behaviour, 9, 596-606.

Merry, R. (1980). The keyword method and children's vocabulary learning in the classroom. British Journal of Educational Psychology, 50, 123-136.

Miller, G. A., \& Gildea, P.M. (1991). How children learn words. In. W. S.-Y. Wang (Ed.), The Emergence of Language: Development and Evolution (Readings from Scientific American) (pp. 150-158). New York: W.H. Freeman.

Modigliani, V. (1976) Effects on a later recall by delaying initial recall. Journal of Experimental Psychology: Human Learning and Memory, 2, 609-622.

Nagy, W.E., \& Herman, P.A. (1987). Breadth and depth of vocabulary knowledge: Implications for acquisition and instruction. In M.G. McKeown \& M.E. Curtis (Eds.), The Nature of Vocabulary Acquisition (pp. 19-35). Hillsdale, N.J.: Lawrence Erlbaum. 
Nation, I.S.P. (1982). Beginning to learn a foreign language vocabulary: A review of the research. RELC Journal, 13, 15-36.

Nation, I.S.P. (1987). Teaching and Learning Vocabulary. Wellington: Victoria University of Wellington English Language Institute, Occasional Publication No. 7.

Nation, I.S.P. (1993). Using dictionaries to estimate vocabulary size: Essential but rarely followed procedures. Language Testing, 10, 27-41.

Nattinger, J. (1988). Some current trends in vocabulary teaching, In R. Carter \& M. McCarthy, (Eds.), Vocabulary and Language Teaching (pp. 60-82). London: Longman.

Rea, C.P., \& Modigliani, V. (1987) The effect of expanded versus massed practice on the retention of multiplication facts and spelling lists. Human Learning, 4, 11-18.

Rea, C.P., \& Modigliani, V. (1988) Educational implications of the spacing effect. In M.M. Gruneberg, P.E. Morris, \& R.N. Sykes (Eds.), Practical Aspects of Memory: Current Research and Issues. Volume 1: Memory in Everyday Life (pp. 402-407). Chichester: Wiley.

Reinking, D., \& Rickman, S.S. (1990). The effects of computer-mediated texts on the vocabulary learning and comprehension of intermediate-grade readers. Journal of Reading Behaviour, 22, $395-411$.

Reynolds, J.H., \& Glaser, R. (1964). Effects of repetition and spaced review upon retention of a complex learning task. Journal of Educational Psychology, 55, 297-308.

Rodgers, T.S. (1969). On measuring vocabulary difficulty: An analysis of item variables in learning Russian-English vocabulary pairs. International Review of Applied Linguistics, 7, 327-343.

Saragi, T., Nation, P., \& Meister, G. (1978). Vocabulary learning and reading. System, 6, 70-78.

Schacter, D.L. (1987). Implicit memory: History and current status. Journal of Experimental Psychology: Learning, Memory, and Cognition, 13, 501-518.

Schmidt, R.A., \& Bjork, R.A. (1992). New conceptualizations of practice: Common principles in three paradigms suggest new concepts for training. Psychological Science, 3, 207-217.

Seashore, R., \& Eckerson, L. (1940). The measurement of individual differences in general English vocabularies. Journal of Educational Psychology, 31, 14-31. 
Seibert, L.C. (1927). An experiment in learning French vocabulary. Journal of Educational Psychology, 18, 294-309.

Siegel, M.A., \& Misselt, A.L. (1984). Adaptive feedback and review paradigm for computer-based drills. Journal of Educational Psychology, 76, 310-317.

Smith, F. (1982). Understanding Reading. Hillsdale, N.J.: Erlbaum.

Stahl, S.A., \& Fairbanks, M.M. (1986). The effects of vocabulary instruction: A model-based meta-analysis. Review of Educational Research, 56, 72-110.

Stanovich, K.E., \& Cunningham, A.E. (1992). Studying the consequences of literacy within a literate society: The cognitive correlates of print exposure. Memory and Cognition, 20, 51-68.

Sternberg, R.J. (1985). Beyond IQ: A Triarchic Theory of Human Intelligence. Cambridge: Cambridge University Press.

Sternberg, R.J. (1987). Most vocabulary is learned from context. In M.G. McKeown \& M.E. Curtis (Eds.), The Nature of Vocabulary Acquisition (pp. 89-105). Hillsdale, N.J.: Lawrence Erlbaum.

Thompson, C.P., Wenger, S.K., \& Bartling, C.A. (1978). How recall facilitates subsequent recall: A reappraisal. Journal of Experimental Psychology: Human Learning and Memory, 4, 210221.

Thorndike, E,L. (1908). Memory for paired-associates. Psychological Review, 15, 122-138.

Underwood, B. (1970) A breakdown of the total-time law in free recall learning. Journal of Verbal Learning and Verbal Behaviour, 9, 573-590.

Webb, W.B. (1962). The effects of prolonged learning on learning. Journal of Verbal Learning and Verbal Behaviour, 1, 173-182.

Whitten, W.B. II, \& Bjork, R.A. (1977). Learning from tests: Effects of spacing. Journal of Verbal Learning and Verbal Behaviour, 16, 465-478. 